\title{
Analisis Pengaruh Penambahan Parameter Medan Magnetik Terhadap Jumlah Dark Matter pada Kurva Rotasi Galaksi Bimasakti
}

\author{
Oqely Wahyudi*, Zulfi, Wildian \\ Jurusan Fisika Universitas Andalas \\ *oqely_wyd@yahoo.com
}

\begin{abstract}
ABSTRAK
Telah dilakukan analisis pengaruh medan magnetik terhadap jumlah dark matter pada kurva rotasi dan dinamika rotasi galaksi Bimasakti. Penelitian ini dilatarbelakangi oleh perbedaan kurva rotasi dari model Sofue dkk (2008) dengan model Sofue (2014). Tujuan dari penelitian ini adalah untuk melihat pengaruh medan magnetik terhadap jumlah dark matter di galaksi Bimasakti. Jumlah dark matter dianalisis melalui pencocokan kurva rotasi dari model dengan hasil pengamatan. Kurva rotasi model dikatakan cocok apabila memiliki nilai error yang paling kecil. Jumlah dark matter akhir yang dihasilkan adalah $33,1 \%$ lebih sedikit dari model Sofue (2014). Nilai ini berasal dari pengkoreksian parameter yang digunakan oleh Sofue (2014) sebesar 31,03\% dan penambahan medan magnetik sebesar 2,07\%. Hasil simulasi juga menunjukkan bahwa dark matter berpengaruh besar dalam menjaga kestabilan rotasi galaksi. Kehilangan medan magnetik tidak terlalu mempengaruhi rotasi galaksi. Simulasi menunjukkan bahwa penambahan medan magnetik menyebabkan revolusi matahari berubah dari 241 juta tahun menjadi 242 juta tahun.
\end{abstract}

Kata kunci: dark matter, kurva rotasi galaksi Bimasakti, medan magnetik

\section{ABSTRACT}

The effect of magnetic field on the amount of dark matter of Milky Way galaxy rotation curve has been investigated. This research was motivated by the difference between the rotation curve in Sofue et al. (2008) and Sofue (2014). The purpose of this study is to investigate the effect of additional magnetic field on the amount of dark matter in Milky Way galaxy. The amount of dark matter was analyzed by matching the rotation curve obtained by the model with the rotation curve from observation. The best matching condition was assumed when the minimum error between the two curves was achieved. It was found that the final amount of dark matter was $33.1 \%$ less than the initial model in which the initial parameter correction contributed about $31.03 \%$ and the additional magnetic field was $2.07 \%$. The simulation showed that the dark matter has significant effect in maintaining the stability of galaxy rotation. Furthermore, the loss of magnetic field did not significantly affect the galaxy rotation, but it could cause a longer sun revolution, from 241 million years to 242 million years.

Keywords: dark matter, rotation curve of Milky Way galaxy, magnetic field

\section{PENDAHULUAN}

Alam semesta yang kita tempati ini terdiri dari 5\% materi biasa, dan 95\% sisanya merupakan dark matter (25\%) dan dark energy (70\%) (Vogt, 2015). Materi biasa merupakan materi yang mampu berinteraksi dengan cahaya (baryonic). Dark energy dan dark matter mengandung kata "dark", artinya belum diketahui kriteria yang sesungguhnya karena tidak berinteraksi dengan cahaya (non-baryonic). Dark matter menjadi masalah yang diprioritaskan oleh komunitas astrofisika saat ini dalam menyempurnakan model fisika teori agar lebih mendekati karakteristik alam semesta yang sesungguhnya (Sarantie dan Refky, 2011).

Salah satu metode untuk mendeteksi dark matter adalah dari kurva rotasi galaksi spiral (KRGS). KRGS adalah kurva hubungan kecepatan tangensial bintang, gas, dan materi galaksi terhadap jaraknya dari pusat galaksi. KRGS memberikan informasi tentang dinamika dan distribusi massa galaksi karena KRGS mengandung informasi jarak dan kecepatan orbit sehingga massa dapat dihitung dengan pendekatan kecepatan orbit sirkular.

Penelitian mengenai KRGS telah dilakukan secara menyeluruh oleh Sofue dkk (2008 dan 2013) dan Sofue (2014). Sofue mengasumsikan bahwa kurva rotasi galaksi dipengaruhi oleh sebuah bulge, disk, distribusi bintang dan gas, serta sebuah dark halo (dark matter). Mereka mendapatkan beberapa parameter untuk semua komponen dalam menyempurnakan model kurva rotasi galaksi Bimasakti agar mendekati keadaan yang sesungguhnya.

Perbedaan terjadi ketika Sofue (2014) menyatakan bahwa model dark halo NFW (Navaroo-Frenk-White) dapat mewakili distribusi dark halo. Model ini berbeda dengan model 
yang digunakannya pada tahun 2008 yaitu model isothermal dark halo. Perbedaan ini menyebabkan kurva yang didapatkan oleh Granados dkk (2012) menjadi tidak tepat dan harus dilakukan pengkoreksian parameter. Pengkoreksian lebih ditujukan kepada model dan jumlah dark matter karena masih sulit dideteksi dan masih bersifat hipotesis. Perubahan ini sangatlah penting karena dark matter merupakan salah satu komponen utama yang mempengaruhi struktur dan nasib alam semesta. Perubahan tersebut dapat diidentifikasi dengan perhitungan dan simulasi.

Metode dalam membuat simulasi dinamika rotasi galaksi sangat beragam. Salah satunya menggunakan metoda Smooth Particle Hydrodynamic (SPH) untuk menjelaskan dark disk galaksi (dark matter). SPH merupakan metode komputasi yang digunakan untuk mensimulasikan mekanika zat padat dan aliran fluida. Simulasi yang menggunakan SPH biasanya dijalankan dengan menggunakan supercomputer sehingga sangat sulit diterapkan pada PC. Oleh karena itu, penelitian ini membuat cara yang lebih sederhana untuk mensimulasikan dinamika rotasi galaksi dalam mengkoreksi distribusi dark matter.

Metode ini merupakan hasil perluasan dari penelitian Sulthon (2013) mengenai penerapan metode Runge-kutta pada gerak orbit planet. Simulasi ini mengunakan hukum II Newton dan teorema Newton mengenai gravitasi. Metode Runge-Kutta digunakan untuk menurunkan persamaan gerak pada hukum II Newton. Metode Runge-Kutta merupakan metode satu langkah yang memberikan ketelitian hasil yang tinggi tanpa turunan dari fungsi tersebut. Metode Runge-Kutta yang sering digunakan adalah Runge-Kutta orde 4, karena metode ini memberikan ketelitian yang lebih akurat dibandingkan dengan metode Runge-Kutta yang berorde di bawahnya (Sulthon, 2013).

\section{METODE}

Data yang digunakan dalam penelitian ini adalah data kurva rotasi galaksi yang terdapat pada Sofue (2013). Data ini merupakan rata-rata dari data observasi kurva rotasi Bimasakti pada Sofue dkk (2008). Data observasi menggunakan metode velocity garis HI (emisi spektrum hidrogen orde pertama), HII (emisi spektrum hidrogen orde kedua), dan CO dan dari satelit VERA (VLBI Exploration of Radio Astrometry). Data ini berisi beberapa parameter yaitu jarak dan kecepatan.

Dalam penelitian ini pengolahan data dilakukan menggunakan software Microsoft Excel dan simulasi menggunakan software Free Pascal. Data kurva rotasi diambil dari Sofue (2013) yang diunduh dari website The Astrophysical Journal. Data tersebut tersedia untuk cakupan jarak 0,00112 kpc hingga $1600 \mathrm{kpc}$. Penelitian ini menggunakan data mulai dari jarak $0,097 \mathrm{kpc}$ untuk menghindari efek gravitasi supermassive black hole di pusat Bimasakti hingga $15 \mathrm{kpc}$ yang merupakan radius dari Bimasakti.

Kurva rotasi galaksi pada data observasi (selanjutnya disebut kurva observasi) ditampilkan dalam bentuk kurva yang merupakan data literatur pada penelitian ini. Kurva rotasi galaksi yang dimodelkan Sofue (2014) (selanjutnya disebut kurva model) akan ditambahkan dengan parameter medan magnetik yang dimodelkan oleh Granados dkk (2012), selanjutnya kurva model akan dicocokkan dengan kurva observasi. Kurva model memiliki beberapa persamaan yang diuraikan oleh subbab berikutnya.

\subsection{Bulge}

Model bulge yang sering digunakan dikenal dengan istilah exponential sphere model atau model eksponensial sferis. Massa jenis bulge $\rho_{b}$ diwakilkan oleh fungsi eksponensial dari radius $R$ dan sebuah skala radius $\alpha$ memenuhi Persamaan (1).

$$
\rho_{b}(R)=\rho_{c} e^{-R / a}
$$

dimana $\alpha=120 \mathrm{pc}$ (skala jarak bulge), dan $\rho_{c}=2,12 \times 10^{2} \mathrm{M}_{\odot} / \mathrm{pc}^{3}$ (densitas pusat bulge) (Sofue, 2014). 


\subsection{Disk}

Model disk yang sering digunakan dikenal dengan istilah exponential disk atau cakram eksponensial. Massa jenis disk $\sigma_{d}$ diwakilkan oleh fungsi eksponensial dari radius $R$ dan sebuah skala radius $R_{d}$ memenuhi Persamaan (2).

$$
\sigma_{d}(R)=\sigma_{r} e^{-R / R_{d}}
$$

dimana

$$
\sigma_{r}(R)=\sigma_{d c}(R)\left[1+\sum_{i=1}^{2} f_{i} e^{-t_{i}^{2}} \sin \left(\frac{\pi t_{i}}{2}\right)\right]
$$

dan

$$
t_{i}=\frac{R-R_{i}}{w_{i}}
$$

dengan nilai $\sigma_{d}=8,44 \times 10^{2} \mathrm{M}_{\odot} / \rho^{2}$ dan $R_{d}=3,5 \mathrm{kpc}$ (skala jarak disk) (Sofue dkk, 2008).

Persamaan (3) merupakan fungsi densitas massa dari Sofue dkk (2008) yang mengasumsikan bahwa massa disk membentuk ring wave. Nilai parameter pada Persamaan (2) dan Persamaan (3) ditunjukkan pada Tabel 1.

Tabel 1 Parameter ring wave pada Persamaan (3)

\begin{tabular}{cccc}
\hline Ring $\mathbf{i}$ & $\mathbf{r}_{\mathbf{i}}(\mathbf{k p c})$ & $\mathbf{w}_{\mathbf{i}}(\mathbf{k p c})$ & $\mathbf{f}_{\mathbf{i}}$ \\
\hline 1 & $\mathrm{r}_{1}=3,5$ & $\mathrm{w}_{1}=1$ & $\mathrm{f}_{1}=0,8$ \\
2 & $\mathrm{r}_{2}=11$ & $\mathrm{w}_{2}=2$ & $\mathrm{f}_{2}=5,0$ \\
\hline
\end{tabular}

\subsection{Dark Halo}

Model yang paling popular untuk dark halo adalah model Navarro-Frenk-White (NFW) karena model ini paling mendekati kurva observasi (Sofue, 2014). Profil densitas model NFW dapat dituliskan pada Persamaan (5).

$$
\rho_{N F W}(R)=\frac{\rho_{N F W}^{0}}{(R / h) /\left[1+(R / h)^{2}\right]}
$$

dengan $\rho^{0}{ }_{\mathrm{NFW}}=0,029 \pm 0,003 \mathrm{M}_{\odot} / \rho^{3}$ (densitas pusat dark halo) dan $h=10 \pm 0,5 \mathrm{kpc}$ (skala jarak dark halo) (Sofue, 2014).

\subsection{Medan Magnetik}

Granados dkk (2012) menggunakan profil medan magnetik galaksi yang digunakan oleh Beck dan Wielebinski (2004) seperti yang ditunjukkan pada Persamaan (6).

$$
B_{\phi} \approx B(R)=\frac{B_{\Theta}\left(R_{1}+R_{\Theta}\right)}{R_{1}+R}
$$

dimana $B_{\Theta} \approx 3 \mu \mathrm{G}$ dan $R_{\Theta}=8 \mathrm{kpc}$ serta $R_{l}=16,5 \mathrm{kpc}$. $B_{\phi}$ adalah medan magnetik tangensial.

Komponen kecepatan linier dari pergerakan gas dinyatakan dalam koordinat silinder memenuhi Persamaan (7).

$$
v_{\text {mag }}^{2}(R)=\frac{R}{4 \pi \rho_{\text {gas }}}\left(\frac{B_{\phi}^{2}}{R}+\frac{1}{2} \frac{d B_{\phi}^{2}}{d R}\right)
$$

dimana $\rho_{\text {gas }}$ merupakan massa jenis gas pada galaksi (Salcedo dan Ruiz, 2008) dimana total massa gas sekitar 10\% dari massa total disk (Granados dkk, 2012). Informasi mengenai distribusi disk dapat dilihat pada Persamaan (2). 


\section{HASIL DAN DISKUSI}

\subsection{Analisis Jumlah Dark Matter}

Kurva rotasi model oleh Sofue (2014) terdiri dari gabungan beberapa kurva kecepatan yang dihasilkan oleh komponen massa galaksi, yaitu bulge, disk, dan dark halo dimana persamaannya telah ditunjukkan pada Bab 2. Gambar 1 (a) menunjukkan kurva model yang dihasilkan oleh bulge, disk, dan dark halo. Terlihat bahwa kurva model menyimpang dari kurva observasi. Nilai error dihasilkan pada kurva model ini sebesar $12,405 \%$ terhadap kurva observasi. Agar kurva model mendekati kurva observasi, maka harus dilakukan pengkoreksian beberapa parameter pada kurva model.

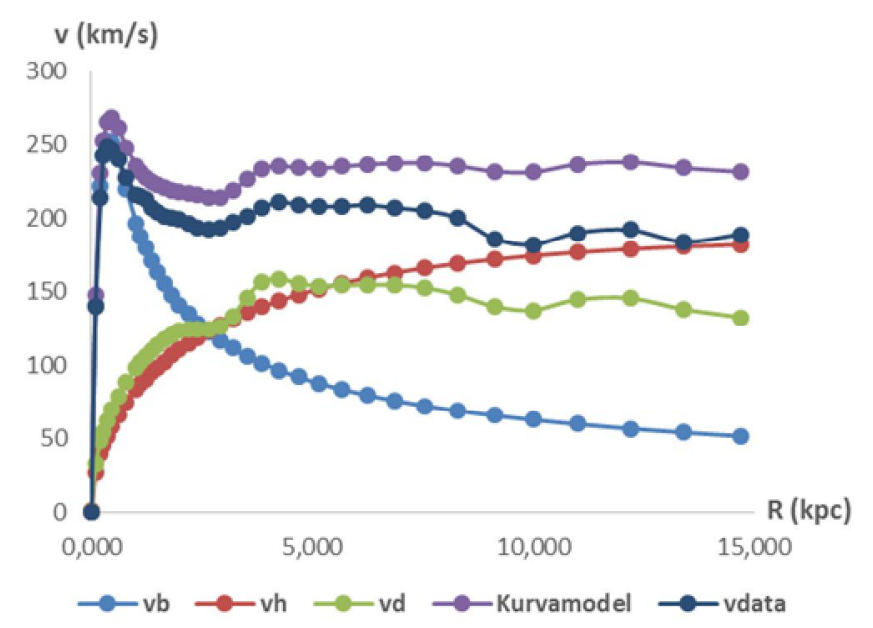

(a)

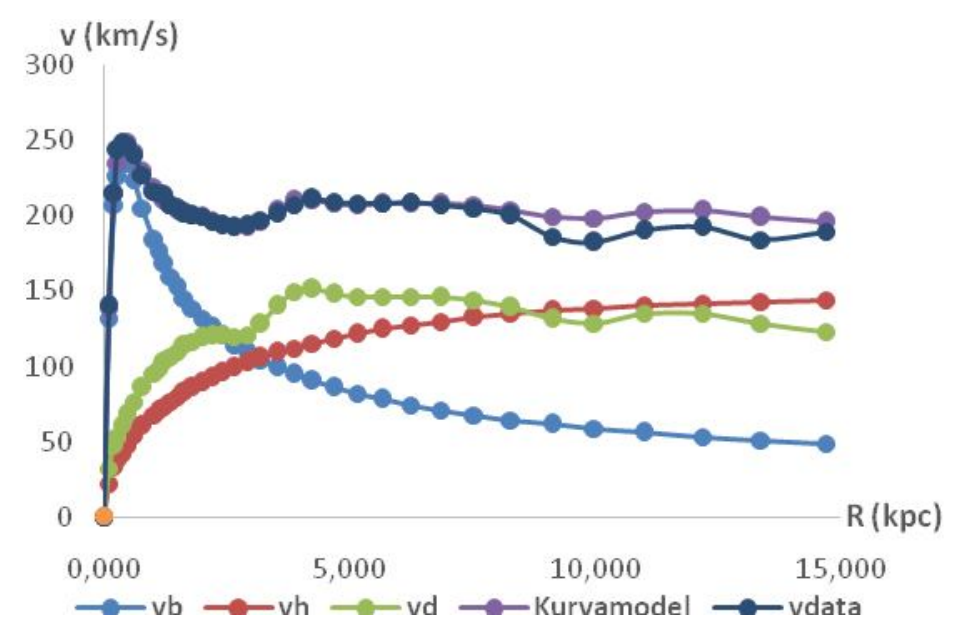

(b)

Keterangan:

$\mathrm{vb}=$ Kurva kecepatan komponen bulge

$\mathrm{vh}=$ Kurva kecepatan komponen dark halo

$\mathrm{vd}=$ Kurva kecepatan komponen disk

Gambar 1 (a) Kurva model awal dan (b) Kurva model setelah dikoreksi

Gambar 1 (b) menunjukkan kurva model yang sudah dikeroksi dimana kurva model hampir berimpit secara sempurna denga kurva observasi. Kurva model memiliki nilai error 1,73 $\%$ terhadap kurva observasi dimana nilai ini merupakan error terminimum yang dapat dicapai. 
Tabel 2 Perubahan nilai pada komponen galaksi

\begin{tabular}{ccccc}
\hline \multirow{2}{*}{ Komponen } & Parameter & $\begin{array}{c}\text { Error yang } \\
\text { diperbolehkan }\end{array}$ & $\begin{array}{c}\text { Kurva Model } \\
\text { awal }\end{array}$ & $\begin{array}{c}\text { Kurva Model } \\
\text { Setelah Dikoreksi }\end{array}$ \\
\cline { 4 - 5 } & & $2,5 \%$ & $0,12 \mathrm{kpc}$ & $0,12 \mathrm{kpc}$ \\
\multirow{2}{*}{ Bulge } & $\alpha$ & $5 \%$ & $2,12.10^{2} \mathrm{M}_{\odot} / \mathrm{pc}^{3}$ & $1,9.10^{2} \mathrm{M}_{\odot} / \mathrm{pc}^{3}$ \\
& $\rho_{c}$ & $5 \%$ & $8,44.10^{2} \mathrm{M}_{\odot} / \mathrm{pc}^{2}$ & $8.10^{2} \mathrm{M}_{\odot} / \mathrm{pc}^{2}$ \\
& $\sigma_{d c}$ & $5 \%$ & $3,5 \mathrm{kpc}$ & $3,3 \mathrm{kpc}$ \\
\hline \multirow{2}{*}{ Disk } & $R_{d}$ & $5 \%$ & $10 \mathrm{kpc}$ & $9,5 \mathrm{kpc}$ \\
& $R_{h}$ & $10,34 \%$ & $2,9.10^{-2} \mathrm{M}_{\odot} / \mathrm{pc}^{3}$ & $2.10^{-2} \mathrm{M}_{\odot} / \mathrm{pc}^{3}$ \\
\hline \multirow{2}{*}{ Dark Halo } & $\rho_{N F W}$ & &
\end{tabular}

Tabel 2 merangkum semua parameter, nilai, beserta error yang digunakan pada Gambar 1 (a) dan (b). Terlihat bahwa beberapa nilai parameter yang digunakan pada Gambar 1 (b) merupakan nilai terminimum yang diperbolehkan oleh nilai error. Namun untuk parameter $\rho_{c}$ dan $\rho_{N F W}$ memiliki nilai yang keluar dari error yang diperbolehkan. Alasannya, untuk parameter $\rho_{c}$ pada bulge yang bertanggung jawab pada kurva rotasi dekat dengan pusat galaksi $(0 \mathrm{kpc}-2 \mathrm{kpc})$. Nilai error $\rho_{c}$ yang didapat setelah koreksi pada penelitian ini sebesar $10,38 \%$ (agar kurva bulge menghasilkan kurva model yang sesuai dengan kurva observasi), sedangkan Sofue dkk (2008) menganjurkan nilai error sebesar 5\%. Untuk parameter $\rho_{N F W}$ pada dark halo yang bertanggung jawab pada kurva rotasi piringan galaksi $(5 \mathrm{kpc}-20 \mathrm{kpc})$. Nilai error $\rho_{c}$ yang didapatkan setelah koreksi sebesar 31,03\%, sedangkan Sofue (2014) menganjurkan nilai error sebesar 5\%. Hal ini kemungkinan masih boleh dilakukan karena jumlah dark matter masih berupa hipotesis.

Selanjutnya, kurva model ditambahkan dengan komponen medan magnetik (selanjutnya disebut kurva model akhir). Kurva model akhir akan dibandingkan dengan kurva model. Gambar 2 (a) menunjukkan kenaikan kurva model dari nilai awalnya akibat penambahan komponen medan magnetik. Kurva model akhir memiliki nilai error $0,384 \%$ terhadap kurva model, namun hal tersebut sangat berpengaruh kepada koreksi komponen dark halo.

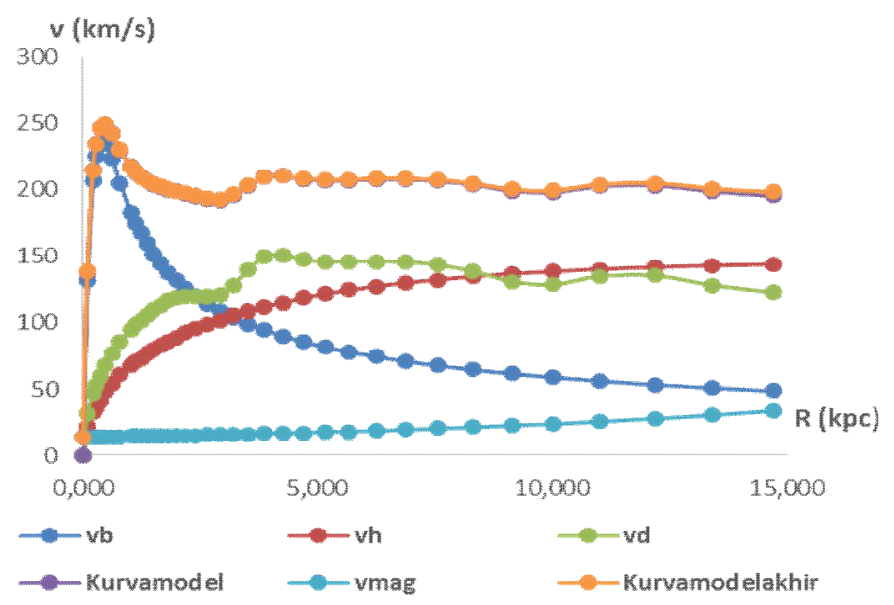

(a) 


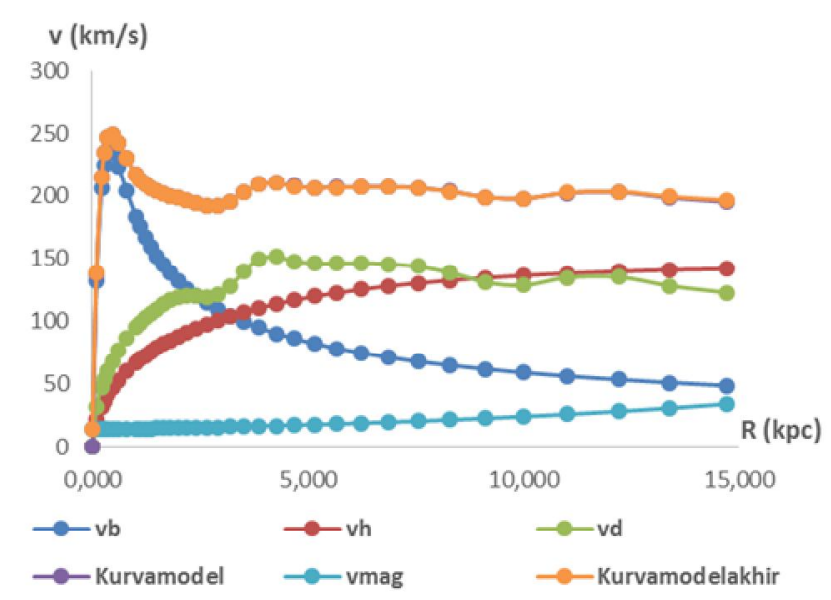

(b)

Keterangan:

$\mathrm{vb}=$ Kurva kecepatan komponen bulge

$\mathrm{vh}=$ Kurva kecepatan komponen dark halo

$\mathrm{vd}=$ Kurva kecepatan komponen disk

vmag $=$ Kurva kecepatan komponen medan magnetik

Gambar 2 (a) Kurva model akhir sebelum dikoreksi dan (b) Kurva model akhir setelah dikoreksi

Pada proses ini, kurva model akhir akan dicocokan kembali dengan kurva model dengan hanya mengkoreksi komponen dark halo. Akibat penambahan medan magnetik tersebut, jumlah dark halo harus dikurangi agar kurva model akhir kembali ke kurva model. Gambar 2 (b) menunjukkan perubahan kurva model akhir yang hampir berimpit secara sempurna dengan kurva model. Proses pengkoreksian ini menghasilkan jumlah dark halo $3 \%$ lebih sedikit dari kurva model.

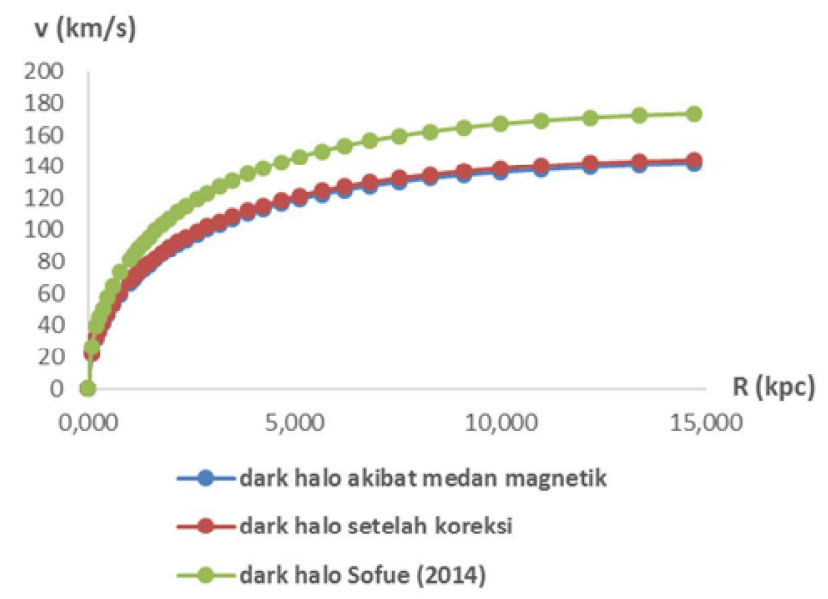

Gambar 3 Perubahan kurva dark halo selama proses pengkoreksian

Gambar 3 menunjukkan perubahan kurva dark halo awal yang mengalami pengkoreksian dan penambahan parameter medan magnetik. Jumlah dark halo yang dihasilkan setelah pengkoreksian lebih sedikit dari kurva model menggunakan parameter Sofue (2014). Telah dijelaskan sebelumnya, dark halo mengalami dua kali koreksi. Koreksi pertama (Gambar 1 (b)) dengan perubahan jumlah dark halo sebesar 31,03\% dari kurva awal dan koreksi kedua (Gambar 2 (b)) dengan perubahan jumlah dark halo sebesar 2,07\%. Penelitian ini menghasilkan jumlah dark halo sebesar 33,1\% lebih sedikit dari jumlah yang digunakan Sofue (2014). 


\subsection{Simulasi Dinamika Rotasi Galaksi}

Simulasi dinamika rotasi galaksi menggunakan program Free Pascal dilakukan untuk menvisualisasikan model kurva rotasi ke dalam model galaksi Bimasakti yang sesungguhnya. Hal ini dapat membantu dalam menganalisa dan memahami peran dari dark matter dan medan magnetik dalam menjaga kestabilan rotasi galaksi.

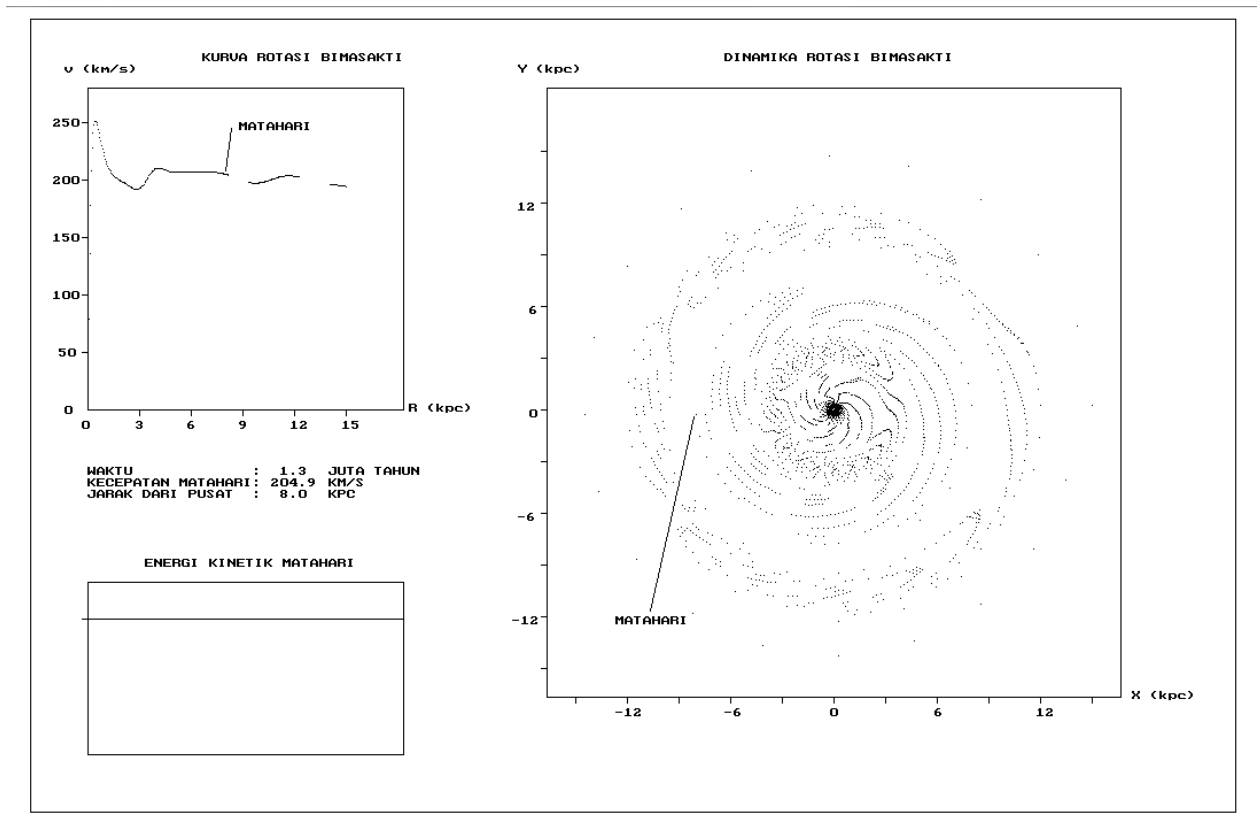

Gambar 4 Tampilan simulasi dinamika rotasi galaksi Bimasakti setelah mengalami pengkoreksian parameter

Gambar 4 memperlihatkan tampilan dari model dinamika rotasi galaksi lengkap dengan kurvanya. Simulasi ini menghasilkan kurva rotasi galaksi yang sesuai dengan data kurva model akhir dengan kecepatan matahari antara $206 \mathrm{~km} / \mathrm{s}-203,2 \mathrm{~km} / \mathrm{s}$ dan jarak matahari dari pusat Bimasakti memiliki rentang 8,0 kpc $-8,1 \mathrm{kpc}$. Periode revolusi matahari mengelilingi Bimasakti sebesar 241 juta tahun. Nilai tersebut tidak terlalu jauh dengan kecepatan, jarak dan revolusi matahari yang diakui saat ini yaitu $200 \mathrm{~km} / \mathrm{s}, 8,0 \mathrm{kpc}$, dan 245 juta tahun.

Simulasi selanjutnya adalah menghilangkan komponen dark halo dan melihat pengaruhnya terhadap rotasi galaksi. Simulasi pada tahap ini memiliki dua asumsi kejadian. Kejadian pertama yaitu menghilangkan parameter dark halo namun tetap mempertahankan model kurva akhir (tetap menggunakan data observasi). Kejadian kedua yaitu menghilangkan parameter dark halo dengan menghasilkan model kurva yang baru (tidak mengacu kepada data observasi). Gambar 5 (a) terlihat bahwa model galaksi yang dihasilkan pada kejadian pertama cenderung menyebar dan tidak stabil. Hal ini disebabkan karena galaksi mengalami kekurangan energi potensial akibat massa dark halo yang hilang, namun energi kinetik (kecepatan pada kurva rotasi) massa bintang tetap dipertahankan (tetap menggunakan data observasi). Hal inilah yang akan terjadi pada galaksi bimasakti apabila dark matter tidak pernah ada. Matahari akan memiliki orbit yang elips dengan jarak terdekat $8 \mathrm{kpc}$ (kecepatan $206 \mathrm{~km} / \mathrm{s}$ ) dan jarak terjauh $10,7 \mathrm{kpc}(154,1 \mathrm{~km} / \mathrm{s})$ relatif terhadap pusat galaksi. Periode matahari pada kasus ini sebesar 319 juta tahun. Oleh sebab itu, asumsi pertama belum mampu menyanggah keberadaan dark matter. 


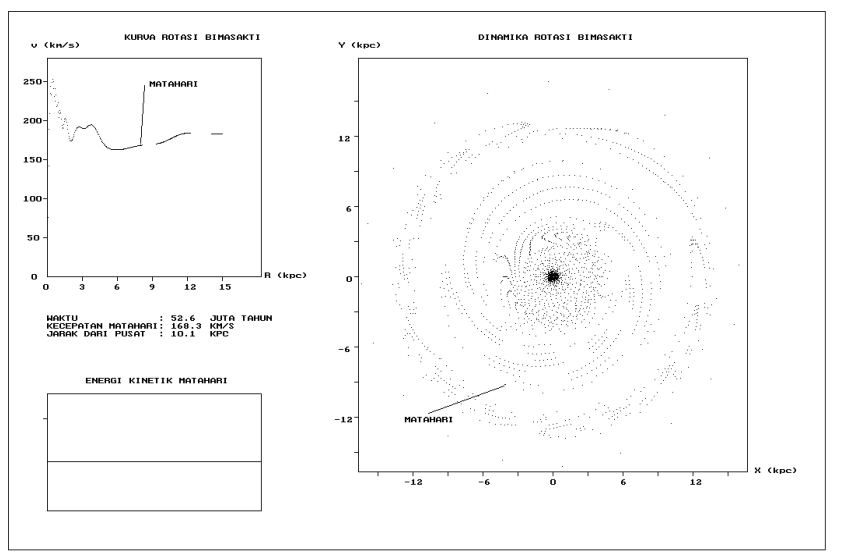

(a)

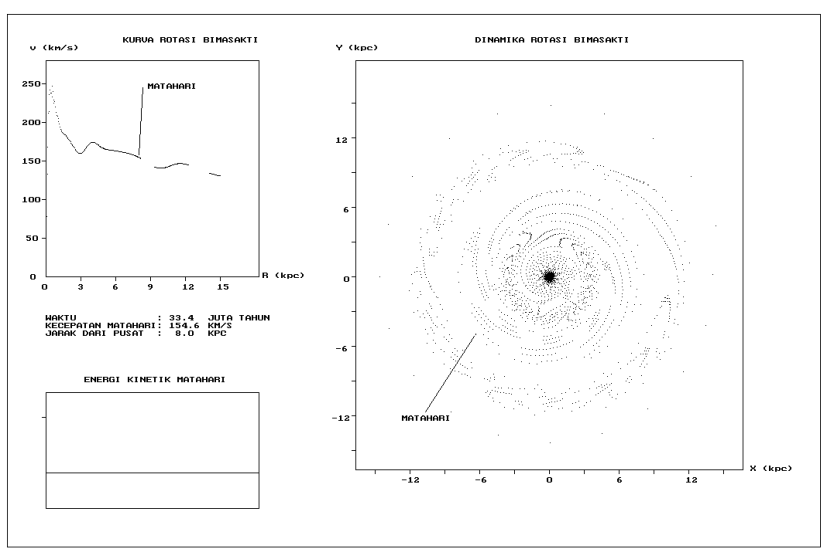

(b)

Gambar 5 Hasil simulasi kurva rotasi tanpa dark halo (a) menggunakan kurva observasi dan (b) tetap menjaga kestabilan kurva rotasi

Gambar 5 (b) terlihat bahwa model galaksi yang dihasilkan pada kejadian kedua cenderung stabil, namun menghasilkan bentuk kurva yang lebih turun. Hal ini disebabkan karena galaksi mengalami kekurangan energi kinetik akibat massa dark halo yang hilang, namun energi potensial massa bintang mengalami penyesuaian agar orbit yang dihasilkan stabil. Apabila dark matter tidak pernah ada, matahari akan memiliki orbit $8 \mathrm{kpc}-8,1 \mathrm{kpc}$, dan kecepatan $154,1 \mathrm{~km} / \mathrm{s}-156,9 \mathrm{~km} / \mathrm{s}$. Matahari memiliki orbit yang stabil dengan periode orbit selama 319 juta tahun. Walaupun demikian, kurva yang dihasilkan tidak cocok dengan hasil observasi sehingga asumsi kedua belum mampu menyanggah keberadaan dark matter.

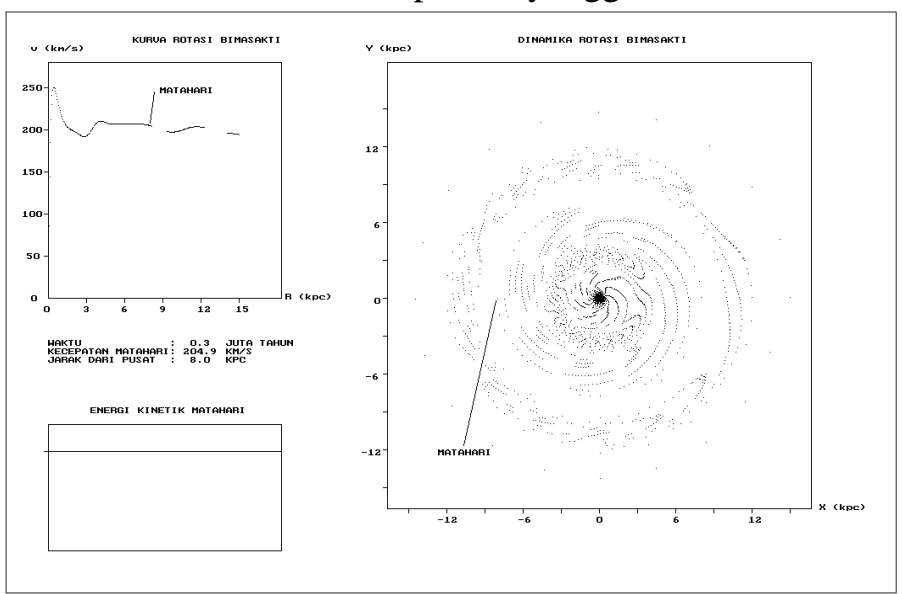

Gambar 6 Model dinamika dan kurva rotasi galaksi tanpa medan magnetik 
Simulasi selanjutnya adalah melihat pengaruh medan magnetik terhadap struktur dan rotasi galaksi. Gambar 6 memperlihatkan perubahan rotasi galaksi akibat pengaruh medan magnetik. Perubahan yang dihasilkan tidaklah terlalu signifikan jika dibandingkan dengan kurva pada Gambar 4. Hal ini disebabkan karena besar tambahan energi yang berasal dari medan magnetik tidak terlalu besar untuk merubah struktur galaksi. Perubahan yang terjadi tidak terlalu besar. Matahari memiliki orbit yang stabil dengan rentang nilai $8 \mathrm{kpc}-8,1 \mathrm{kpc}$ dengan kecepatan $203,2 \mathrm{~km} / \mathrm{s}-204,9 \mathrm{~km} / \mathrm{s}$. Periode revolusi matahari 242 juta tahun yang tidak begitu jauh dengan periode yang diakui saat ini yaitu 245 juta tahun.

\section{KESIMPULAN}

Penelitian ini menunjukkan bahwa penambahan medan magnetik mengakibatkan jumlah dark halo 33,1\% lebih sedikit dari model yang diajukan Sofue (2014). Hasil simulasi memperlihatkan bahwa dark halo menjaga kestabilan dinamika galaksi. Apabila dark halo dihilangkan, maka simulasi untuk asumsi pertama (menggunakan kurva observasi) dihasilkan kurva rotasi yang tidak stabil, sedangkan simulasi untuk asumsi kedua (menjaga kestabilan rotasi galaksi) dihasilkan kurva yang lebih menurun dengan kala revolusi matahari selama 319 juta tahun. Medan magnetik tidak mampu menggantikan peran dark halo pada galaksi karena memiliki jumlah yang jauh lebih kecil. Hasil ini juga memperlihatkan bahwa kurva medan magnetik yang dimodelkan Granados ddk (2012) lebih besar 5 kali dari yang seharusnya (berdasarkan persamaan yang diajukannya).

\section{DAFTAR PUSTAKA}

Beck, R. dan Wielebinski, R., 2004, Cosmic Magnetic Fields, Spinger, Vol. 5, Hal 1-67.

Granados, B. R., Battaner, E., Clavo, J., Florido, E. dan Rubino-Martin, J.A., 2012, Dark Matter, Magnetikic Field, and the Rotation Curve of the Milky Way, The Astrophysical Journal Letter, Vol. 755, Hal 1-5.

Salcedo, F.J.S. dan Ruiz, M.R., 2008, Constraining The Magnetic Effects on HI Rotation Curves and The Need for Dark Halos, The Astrophysical Journal, Vol. 11, Hal 1-12.

Sarantie dan Refky, N., 2011, Kajian Teori dan Eksperimen Dark Matter dari Perspektif Kosmologi dan Supersimetri, Universitas Airlangga, Surbaya.

Sofue, Y., Honma, M. dan Omodaka, T., 2008, Unifield Rotation Curve of the GalaxyDecomposition into de Vaucouleurs Bulge, Disk, Dark Halo, and the 9-kpc Rotation Dip, Publication of the Astronomical Society of Japan, Vol. 61, Hal 1-11.

Sofue, Y., 2013, The Mass Distribution and Rotation Curve in the Galaxy, Publication of the Astronomical Society of Japan, Vol. 65, Hal 1-14.

Sofue, Y., 2014, Rotating and Mass in the Milky Way and Spiral Galaxy, Publication of the Astronomical Society of Japan, Vol. 69, Hal 1-34.

Sulthon, M.B., 2013, Analisa Solusi Numerik Model Gerak Planet dengan Metode RungeKutta, Skripsi, Universitas Jember, Jember. 